\title{
Prelingual non-syndromic genetic deafness
}

INSERM

\section{Source}

INSERM. (1999). Orphanet: an online rare disease and orphan drug data base. Prelingual non-syndromic genetic deafness. ORPHA:216445

Prelingual non-syndromic genetic deafness is a rare, genetically highly heterogeneous otorhinolaryngologic disease, resulting from inner and/or middle ear or auditory nerve anomalies, typically characterized by bilateral, severe to profound hearing loss (mean sensorineural hearing impairment of $60 \mathrm{~dB}$ or more for $500-, 1,000-$, and 2,000- $\mathrm{Hz}$ frequency tones in the better ear) which occurs before the onset of speech development and is not associated with visible external ear abnormalities or any other medical problems. It is usually nonprogressive and impedes oral language acquisition. 